
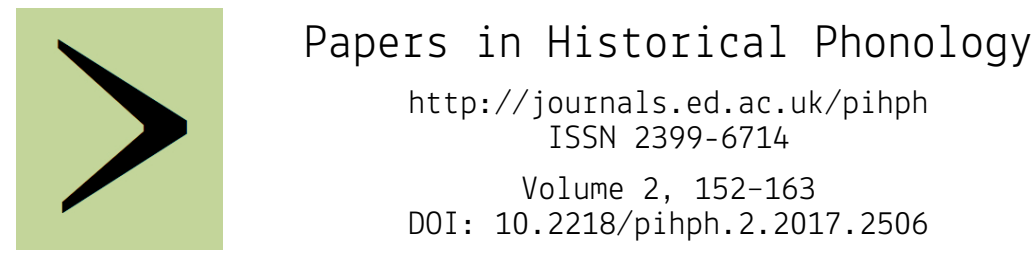

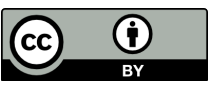

Licensed under a Creative

Commons 4.0

International License

\title{
Reality in a soft science: the metaphonology of historical reconstruction
}

\author{
ROGER LASS \\ Angus McIntosh Centre for Historical Linguistics
}

\begin{abstract}
All disciplines that deal with (apparent) recovery of objects from the past are faced by a fundamental question: what is the metaphysical status of these objects? Are they realia of some kind, or are they merely epistemic objects with no substance? This could be summed up from a debate still going on in quantum physics: do quantum systems have a real existence, or are they merely devices for calculation? In this paper I sum up the advantages of having an ontology, and the disadvantages of assuming that reconstructed linguistic objects are not real. I also discuss the uniformitarian position that makes this an unproblematic claim. I also deal with the neo-Saussurean claim that reconstructed items have no reality in themselves, but solely in terms of the systems they are in; and I suggest that this position (held by Meillet and Kuryłowicz among others), is fundamentally perverse.
\end{abstract}

What is the status of the objects linguistic historians reconstruct (segments, phonetic values, etymological pathways, etc.)? Are they the pure 'formulaic' constructs that Meillet claimed famously he believed they were (see below)? Or could they have true ontological value as in the various kinds of realism practiced (usually unreflectively) by historians? I engage here with three main issues. First, do the objects we reconstruct form part of an ontology, or are they content-free outputs of protocols? Second, given my more or less realist answer, what is the 'substance' that makes these outputs ontic? And third, derivatively, what is the status of 'indirect' reconstructions? For instance, projecting a common ancestor ${ }^{*} \mathrm{k}$ from a cognation $[\mathrm{k}]:[\mathrm{h}], 1$ but disallowing a direct etymological sequence ${ }^{*} \mathrm{k}>{ }^{*} \mathrm{~h}$, rather claiming the necessity or at least high desirability of an intervening *x. This would be required by a kind of 'Darwinian' gradualism, supported by

1 Reconstructed items are starred. Where only phonetic characterisation and not reconstructed status are at issue, I use IPA symbols in square brackets. 
uniformitarianism. ${ }^{2}$ Thus the longer etymology would be the null hypothesis: in this context length = parsimony. (This would not be a violation of Occam's Razor, as that says only that entities should not be multiplied praeter necessitatem [beyond necessity]; and in this case it might be that the addition of * $x$ to the etymological chain would not be beyond necessity, but derived by principle.)

The polar philosophical stances in the interpretation of theorycreated objects could be described as: ${ }^{3}$

(a) Instrumental/Epistemic: theories are merely devices for calculation and do not generate realia. ${ }^{4}$

(b) Realist/Ontic: theories generate extra-mental realia of some kind.

This dichotomy was the underlying issue Galileo came to grief over; he insisted that the heliocentric universe was a real object, while his adversary Cardinal Bellarmino was happy to allow him to teach it as long as he didn't claim that it was real. Galileo nearly went to the stake for his ontological commitment; he did spend the last nine years of his life under house arrest for it. The issue is still with us: probably the classic modern epistemic theory is the Copenhagen Interpretation of quantum mechanics. This holds that attempts to penetrate the mathematics defining the wave function ${ }^{5}$ are pointless, that it is a pure calculating instrument (which gets the answers right - but the objects or states that appear in the answer have no existence until they've been observed). This stance, characterising the wave function as a mathematical abstraction which magically produces the right answers rather than part of the world's furniture, is being fiercely battled by a

\footnotetext{
2 I return to uniformitarianism toward the end of this paper. For now I define it this way: 'there are no miracles [...] the principles governing the world (= the domain of enquiry) were the same in the past as they are now' (Lass 1997, 25: italics original). 3 This dichotomy is less subtle and somewhat different from the one used in current philosophy of physics. But I think it is satisfactory for this linguistic discussion, in which quite different matters arise. For the issues as treated in current philosophy of physics see Atmanspacher (2002). I am grateful to Julia Questa for calling this paper to my attention.

4 Actually the modern definition of 'epistemic' makes it less of a synonym for 'instrumental'; to be precise, an epistemic theory is one consisting only of mental representations - this does not actually imply instrumentalism sensu stricto. But practically being ontology-free is what counts in both definitions.

5 The wave function of a quantum system (e.g. a proton or an atom) is a variable quantity whose values predict the probabilities of the particle being in a particular location at a particular time.
} 
small cadre of realists (see Meralli 2015). ${ }^{6}$ The classic ontic theories like Einstein's General and Special theories of relativity and Darwin's theory of natural selection are intact. One day perhaps the ontic supporters will show definitely that Schrödinger's cat must be either alive or dead at any given moment regardless of observation - so far it appears not to have happened. ${ }^{7}$ The distinction is clearly laid out in Chakravartty (2015, section 1.2$)$ :

Semantically, realism is committed to a literal interpretation of scientific claims about the world. In common parlance, realists take theoretical statements at 'face value'. According to realism, claims about scientific entities, processes, properties, and relations, whether they be observable or unobservable, should be construed literally as having truth values, whether true or false. This semantic commitment contrasts primarily with those of so-called instrumentalist epistemologies [...], which interpret descriptions of unobservables simply as instruments for the prediction of observable phenomena, or for systematizing observation reports. Traditionally, instrumentalism holds that claims about unobservable things have no literal meaning at all $[\ldots . .]^{8}$

\footnotetext{
${ }^{6}$ There is a competing interpretation of quantum mechanics, the Many-Worlds theory, in which each observation produces a new universe, identical to the one in which the observation is made except for the results of the observation. Since by definition the parallel universes are not real in our current universe, and do not pre-exist but are brought into existence by observation, this theory is probably epistemic. It is also untestable as are most other interpretations of quantum mechanics, since they all make the same (correct) predictions. The pioneering work in this area is the exceedingly difficult and technical DeWitt \& Graham (1973). There is a more popular and accessible account in Gribbin (2012: ch. 11).

7 Schrödinger's cat is a thought experiment dating from 1935, designed to illustrate what the physicist Erwin Schrödinger took to be the paradoxical properties of the Copenhagen Interpretation. A cat is shut in a box with a radioactive substance, and whether or not the substance will emit a particle at any time is unpredictable (this is a general statistical property of radiation). If there is no particle emitted the cat will be alive when you open the box, if a particle is emitted it will be dead. If quantum superposition (existence of multiple simultaneous states) is possible, and the Copenhagen interpretation is valid, then as long as the box is closed the cat is both alive and dead. Its final state can be known only when an observation is made.

8 This view is characterised nicely in a letter of Einstein (Jammer 1982, 73-4): "The present quantum theory is unable to provide the description of a real state of physical facts, but only of an (incomplete) knowledge of such. Moreover, the very concept of a real factual state is debarred by the orthodox theoreticians. The situation arrived at corresponds almost exactly to that of the good old Bishop Berkeley." (George Berkeley, 1685-1773, Bishop of Cloyne, was an Irish philosopher who espoused an extreme idealism, denying the existence of any material world: things come into existence only as a result of their being perceived.)
} 
There is a paradoxical split in our field. On the one hand, it is and probably always has been dominated by some kind of realism (if not as an explicit theoretical tenet). But our realia are almost entirely generated by protocols or projection of synchronic methods and ideas and theoretical positions back into the historical arena. Realist reconstruction was in fact being practiced at least since the early $19^{\text {th }}$ century, without the issue of realism even arising (what else could these things be but real?). When Grimm (1822) invented the formal notion of Lautverschiebung, he assumed that 'things' of some sort like tenues (stops) and aspirata (aspirates, actually his name for fricatives) had taken part in the shift, that these things had locations as well as manners of articulation (labiales, gutturales). Further, they moved from one stricture degree (Stufe 'grade') to another within a real space. For him the past had an ontology. ${ }^{9}$

On the other hand, there is a famous and influential view that the primary realia themselves are not the outputs of reconstructive praxis, but only their relations are. Meillet, under the influence of his mentor Saussure, posited an influential view of this kind, later developed and made more explicit by others. He denied that the major types of reconstructed object that would seem to be suitable for ontic interpretation (segments, tones, words) were real. In the larger project of history their potential material values were important only insofar as they defined relations within systems, and their historical value was apparently solely instrumental. What was real for him would in the commonsense view be even less real than a reconstructed phone(me): it was an abstraction with no possible material existence.

In a methodological exposition of comparative method (1964 [1937], 41-2), Meillet gives examples like

skr. $d h=$ gr. $\theta=$ arm. $d=$ germ. $d$

and describes the meaning of his praxis this way (p. 47): "On pourra convenir de designer"10 such a correspondence set as $* d h$, and if we wished call it an "occlusive sonore"11. Then comes what appears to be a complete reversal: "les 'restitutions' ne sont que les signes par lesquels on exprime en abrégé les correspondences"12. Further, they do not precisely represent spoken language: he says sarcastically that IndoEuropean cannot be reconstructed "tel qu'il a été parlé" 13 - as if

\footnotetext{
${ }^{9}$ See the discussion in Lass (2015a, section 4.2).

10 "we could agree to designate" (translations mine [RL])

11 "sonorant stop"

12 "'reconstructions' are nothing but signs by which we summarise correspondences"

13 "just as it was spoken"
} 
anyone ever thought seriously that it could. Rather, reconstructed IndoEuropean is only "un système défini de correspondances entre des langues historiquement attestées"14 (p. 47, italics Meillet's).

Meillet claimed to hold the Saussurean position that phonetics is not part of linguistics (even though he used phonetic argument in the same way as Saussure did in his own reconstructive work), ${ }^{15}$ and some of his most brilliant analyses concern phonetic realities. He believed that what really counted in reconstructing systems was not the properties of their individual members (which were of no real interest) but what later came to be called in a post-Jakobsonian mode their 'mere otherness'. In the later structuralist tradition this even came to be taken as the 'signifiant' of the phoneme itself (van Schooneveld 1996, 30).

The radical structuralist anti-phonetic position is summed up explicitly by Kuryłowicz, in a rather bizarre definition of 'linguistic' (1964, 11, emphasis his):

\begin{abstract}
Physiological speculations [...] do not grasp the linguistic essence of [...] changes, the shift of the internal relations of the elements in question being the only pertinent fact. Once we leave language sensu stricto and appeal to extralinguistic factors, ${ }^{16}$ a clear delimitation of the field of language research is lost.
\end{abstract}

In fact he says (1964:12) that "the accumulating deviations from traditional pronunciation are not linguistic changes"; only phonemicisations are. The first question to ask is precisely what it is that becomes phonemicised, and how if not by phonetic changes that make it contrastive. Another issue that does not seem to be problematic in this kind of structuralism is this: how is it that given a set like \{Sanskrit pitar-, Latin pater, Old English fæder, German Vater\}, supposedly reconstructed on the basis of pure 'relations', we always

\footnotetext{
14 "a precise system of correspondences among the historically attested languages"

15 Cf. Saussure (1879). For detailed discussion of Saussure's ultimate epistemicism with regard to history, and exclusion of a notion of phonetic change (in fact of phonetics) from 'scientific' linguistics, see Joseph (2012, 380-88).

16 This is an interesting utterance for the man who developed the roots of laryngeal theory on the basis of a partly phonetic interpretation of Hittite orthography. Specifically the fact of something being in a word-position where nothing was previously reconstructed, and having these previous zeroes develop into objects that define properties like vowel quantity and quality. Note the Saussurean echo, taken as normal for historical linguistic research, and particularly reconstruction. For an even more extreme view see Zawadoski (1962), and the discussion of his reconstructional praxis in Lass (1993).
} 
seem to come out with a labial initial?17 This is profoundly disingenuous (the term would apply both to Meillet and Kuryłowicz); there is really no way of avoiding phonetic operations, even in something as apparently basic, and to the structuralist imagination abstract, as constructing phoneme systems.

Phonology without phonetics is perverse. ${ }^{18}$ Though many distinguished linguists have come close to taking this kind of position about the past, few have managed to hold it consistently. Even the hyperstructuralists for the most part drift into phonetic praxis when necessary. But we can argue rationally that reconstructed linguistic objects of any kind must be realist, and realist in a particular way. Here is an excellent recent statement of why this must be the case (Anthony \& Ringe 2015, 199):

[...] each protolanguage that we reconstruct must be an approximation of some real language spoken by a real community, for two different reasons. One basis of our confidence is the nature of the 'comparative method' by which we reconstruct protolanguages: it exploits the observed regularity of sound change by means of simple mathematics, yielding categorical results that can be replicated by other researchers and checked both for internal consistency and against information from other sources [...]. The other reason for our confidence is the Uniformitarian Principle (UP) [...] As usually applied in linguistics, the UP holds that unless external conditions can be shown to have changed in some way that can be proved to have an impact on human language, we must assume that the structures of past languages [...] fell within the same ranges as those of languages that can still be observed and studied $[\ldots]$

If this is so, then realism of a fairly ordinary kind in fact becomes necessary:

If straightforward mathematical reconstruction yields a grammar fragment that falls within the observed range for modern native languages, we can reasonably infer that it corresponds to some real language of the past spoken by some real speech community, because experience shows that living languages do not exist apart from native speech communities.

If we accept this line of argument, then when we describe languages existing only as reconstructed, or much the same thing, only in written or epigraphic form, there must be some 'substance' to our descriptions

\footnotetext{
${ }^{17}$ Except in the cases of Old Irish athir, Armenian hayr, where the loss in one case and lenition in another have to be described phonetically.

${ }^{18}$ A relatively recent example of this was the (now fortunately forgotten as far as I can tell) non-phonetic 'phonology' of James Foley (e.g. 1977), in which names like 'velar' were said to represent abstract, pure phonological properties, but always seemed to turn out as things like $[\mathrm{k}, \mathrm{g}, \mathrm{x}]$.
} 
of the objects we cause to emerge from the past. In doing etymologies 19 or filiations based on such objects, we have to assign a specified 'thinghood' to whatever it is that becomes whatever else. At least we have to for our talk to have any interesting content. If we take the hyperstructuralist view that phonemes are 'mere otherness', then we could call the elements constituting systems @ and \&; and as long as @ contrasts with $\&$ at $t_{1}$ and there is a merger in $\&$ at $t_{2}$ we could write an etymological sequence @ > \&, and incorporate it into a history. This would of course be of no interest in terms of an actual subject matter. The pure structuralist interpretation of past objects and their behaviour in history is intellectually empty. "The past is a foreign country' of course, but the uniformitarian principle says it has to look a lot like the present.

But what kind of reality do past objects have? Let us take the simplest case, reconstruction of a protoform on the basis of a cognate set. If reconstructions are realia, what does the asterisk allow us to posit? My example here is the initial segment of the Indo-European root meaning 'heart' and its fate in Germanic. The correspondence set \{Latin cord-, Old Irish cride, Old English heorte, Old Norse hjarta\}, using standard procedures, makes us reconstruct PIE *kerd-, and then via Grimm's Law Proto-Germanic *xert-. The operation involves phonetic claims. Most simply, we appear to be saying that in some way (leaving off the stars for the moment) there was a historical phonetic narrative like this: the actual phonetic element [k] became $[\mathrm{x}]$. (It would seem impossible for something to become something else unless both had some real existence.) In early Old English the orthographical $h$ - may have stood for either [x] or [h]; in late Old English there is no doubt that it was [h], as it is now in those English dialects where it survives. I deliberately used this example because there's an uncertainty, and that is due to what can only be a phonetic question. If everything starts with PIE [k] and then we get Proto-Germanic [x], we have to invoke a subnarrative, to get $[\mathrm{x}]$ to $[\mathrm{h}]$. And all these operations, which are part of a filiation and in fact a major part the definition of Germanic, are purely phonetic. We not only have to give the ultimate protoform a phonetic shape, we have to claim that the Grimm's Law spirantisation of voiceless stops, whose input was [k], had an output [x], and that in all the Germanic dialects, initially before a vowel, at some point this

\footnotetext{
19 Etymologies in the narrative sense of the Corpus of Narrative Etymologies (CoNE), not in the Greenbergian sense of clusters of things that look similar if you stare hard, or even in the classic historical dictionary sense of collections of (properly justified) cognates and comments, and perhaps projection of a protoform.
} 
became $[\mathrm{h}] .{ }^{20}$ Not only are the segmental outputs unproblematically real, so are the processes that generate them. And at this stage of our reconstruction the systems these elements exist in are of no interest: that kind of theoretical interpretation can come only after the realist interpretation of what we have reconstructed. (In fact the existence of reconstructed systems is fully dependent on that of surface phonetic realities.)

The way through structuralist obfuscation then is to instantiate the Anthony \& Ringe characterisation, which I take as now canonical: a reconstructed language (and therefore all the elements in it and all its behaviours, at all levels) "corresponds to some real language". We now have to specify what "corresponds to" might mean in practice. How do we assign a substantial phonetic value to a reconstructed segment? One way is via a thought experiment that we might call 'projected transcriptional response'. Let us reconstruct *x (and as we must now call it, a velar) ${ }^{21}$ for some category in a dead language. (Whether orthographically attested or not is irrelevant.) We would then be making a reality claim that at present (ever?) can be tested only in principle, or (see below) indirectly. But in general such claims allow us to tell useful stories that possess the best attribute a hypothesis can have: not truth but verisimilitude. Assuming we are properly trained phoneticians, we should have to transcribe an utterance of ${ }^{*} x$, if we came to hear one, as some kind of back fricative, and in fact our transcription of it as * $\mathrm{x}$ means that we are making that ontological claim. A characterisation and partial justification might go like this (Lass 2015b, 120):

\begin{abstract}
All our symbols are 'broad', but some are broader than others. The level we choose might best be called 'poorly resolved broad' transcription (Laing \& Lass 2003, 264), which is in general, I think, the right way to represent historical sound substance. That is, we hope that our reconstructions are well enough supported so that if a responsible phonetician equipped with a time-machine were able to hear the items represented, the symbol in question would not be too outlandish a transcriptional response. This is partly standard wishful thinking, and partly our assessment of the results of work in comparative and historical linguistics over the past two centuries.
\end{abstract}

\footnotetext{
${ }^{20}$ It is not entirely clear when the second lenition of *k occurred. The first unequivocal data is from the early $8^{\text {th }}$ century. See CoNE, CC s.v. ((XW1)). Note that we are also invoking an ontological claim by assigning ${ }^{*} \mathrm{x}$ a location in real (if hard to specify) time. There are cases of course where the distances are too great for us to do this (when did Grimm's Law start?), but in such instances we can locate reconstructed items relatively (Verner's Law had to follow the Grimm's Law spirantisation of voiceless stops).

${ }^{21}$ Of course in any given variety this category might be uvular; *x really stands, most safely, for a back fricative.
} 
We could then check this imagined response against present day languages in the same family for which we would want to reconstruct ${ }^{*} x$. To avoid the special complications of initial position, let us look at those languages that have a dorsal fricative in another place where we would reconstruct *x: say the words for 'night' (all certainly cognate, with a framework Proto-Germanic ${ }^{*} n V x t<$ Indo-European $\left.{ }^{*} n V k t-\right)$ in German, Dutch and Scots. Here the ${ }^{*} x$ position in the present day spoken languages is occupied by $[\mathrm{x}]$ or $[\chi]$ or $[c] .{ }^{22}$ We have reconstructed objects that show by their reflexes that they were particular realia, and further justify the realist claim. This would seem to be necessary if the classical expression ex nihilo nihil fit ${ }^{23}$ is true, or true enough to be part of a uniformitarian theory. ${ }^{24}$

We can take this ontological commitment it a step further. Is there a case for adding objects to a reconstructed pathway supported not by actual elements, but rather by principle? In other words, in a realist framework, can objects (in this case phonetic objects) be reconstructed safely ex nihilo (apparently)? I think we are at times forced to do this by the Uniformitarian Principle. Take for example a clear cognation involving [k] and zero, with no other items. Can we turn the cognation into a change $[\mathrm{k}]>\varnothing$ directly? The uniformitarian answer is almost certainly no, because in observed languages ${ }^{25}$ this does not usually happen. Voiceless stops, except in certain fast speech processes, most commonly delete only via a lenition sequence in which [h] is the last stage before zero, i.e. the uniformitarian pathway is $[\mathrm{k}]>[\mathrm{x}]>[\mathrm{h}]>\emptyset$.

And in English, the one language which shows zero in the fricative position in 'night', there is also clear but little-known evidence not only for $[\mathrm{x}]$ in some dialects (e.g. Scots), but of a stage [h] varying with zero in the $16^{\text {th }}$ and $17^{\text {th }}$ centuries in this class of words (night, bright, etc.: see Lass 1999, section 3.5.1). This allows us to turn our reconstructive hypothesis into a prediction through the testimony of contemporary phoneticians. And we also know that in the relevant period the data

\footnotetext{
22 The fact that in some languages in some positions the reflex of our ${ }^{*} \mathrm{x}$ is prevelar makes it even more real in a sense, as it has to have been back to have assimilated to nonback. As does the fact that the *xt shows up as a long ('geminate') consonant in Swedish natt [nat:], which shows again that there has to have been a real object in that position.

23 "nothing comes from nothing"

24 There is at least one exception to this, and that is in phonotactically rather than phonetically motivated epenthesis, e.g. the insertion of initial $e$ in Spanish to disallow initial [sC] clusters: escorbuto 'scurvy' < Latin scorbūtus. This is produced not by copying of features, but by a pure phonotactic constraint in which the vowel appears out of nowhere and has no etymological ancestor.

${ }^{25}$ At least those I happen to know of, which for all linguists counts as 'universally'.
} 
gives us the variation in a change in progress which the uniformitarian principle also predicts. So this successful prediction adds an element of verisimilitude to a hypothesis whose elements derive purely from a theoretical claim. And at nowhere in this procedure are 'systems' of contrasting 'others' necessary - they may well be interesting, but they are totally derivative of, and make sense only in terms of, the phonetic realities.

So the choice then of real-language-like outputs of reconstruction and uniformitarianism, here applied to process as well as structure, gives us what looks like a full and unproblematic vindication of a realism as radical as structuralist instrumentalism. And, to quote one of the greatest non-structuralist linguists of our age, phonetics, rather than being a separate discipline, is in fact "the indispensable foundation of all study of language" (Sweet 1877, b). ${ }^{26}$

\section{Comments invited}

PiHPh relies on post-publication review of the papers that it publishes. If you have any comments on this piece, please add them to its comments site. You are encouraged to consult this site after reading the paper, as there may be comments from other readers there, and replies from the author. This paper's site is here:

https://doi.org/10.2218/pihph.2.2017.2506

\section{Acknowledgements}

Thanks to Roly Sussex, Julia Questa and Anette Rosenbach for helpful comments.

\section{Author contact details}

Roger Lass

Angus McIntosh Centre for Historical Linguistics

University of Edinburgh

Edinburgh

EH8 9AD, UK.

lass@iafrica.com

26 In the preface to Sweet (1877), the first page of which this quotation comes from, the recto is not numbered, but only has a 'b' at the bottom. The verso is 'vi'. 


\section{References}

Anthony, David W. \& Don Ringe. 2015. The Indo-European homeland from linguistic and archaeological perspectives. Annual review of Linguistics 1. 199-219.

Atmanspacher, Harald. 2002. Determinism is ontic, determinability is epistemic. In Atmanspacher, Harald \& R.C. Bishop (eds.). Between chance and choice, 49-74. Thorverton: Imprint Academic.

Chakravartty, Anjan. 2015. Scientific Realism. In Zalta, Edward N. (ed.) The Stanford Encyclopedia of Philosophy (Fall 2015 Edition) http://plato.stanford.edu/archives/fall2015/entries/scientificrealism/.

CoNE = Lass, Roger, Margaret Laing, Rhona Alcorn \& Keith Williamson. 2013-. A Corpus of Narrative Etymologies from Proto-Old English to Early Middle English and accompanying Corpus of Changes. Version 1.1. Edinburgh: The University of Edinburgh. http://www.lel.ed.ac.uk/ihd/CoNE/CoNE.html.

DeWitt, Bryce \& Neill Graham (eds.). 1973. The many-worlds interpretation of quantum mechanics. Princeton: Princeton University Press.

Foley, James. 1977. Principles of theoretical phonology. Cambridge: Cambridge University Press.

Gribbin, John. 2012. In search of Schrödinger's cat. London: Black Swan.

Grimm, Jacob. 1822. Deutsche Grammatik. Erster Teil. 2nd edition. Göttingen: Diedrich'sche Buchhandlung.

Jammer. Max. 1982. Einstein and quantum physics. In Holton, Gerald \& Yehuda Elkana (eds.). Albert Einstein: historical and cultural perspectives; the centennial symposium in Jerusalem, 56-76. Princeton: Princeton University Press.

Joseph, John. 2012. Saussure. Oxford: Oxford University Press.

Kuryłowicz, Jerzy. 1964. On the methods of internal reconstruction. In Lunt, Horace (ed.). Proceedings of the 9th International Congress of Linguists, 9-36. The Hague: Mouton.

Laing, Margaret \& Roger Lass. 2003. Tales of the 1001 nists: the phonological implications of litteral substitution sets in some thirteenth-century South-West Midland texts. English Language \& Linguistics 7(2). 257-78.

Lass, Roger. 1993. How real(ist) are reconstructions? In Jones, Charles (ed.). Historical linguistics: problems and perspectives, 156-89. London: Longman.

Lass, Roger. 1997. Historical linguistics and language change. Cambridge: Cambridge University Press. 
Lass, Roger. 1999. Phonology and morphology. In Lass, Roger (ed.). The Cambridge history of the English language. III, 1476-1776, Cambridge: Cambridge University Press.

Lass, Roger. 2015a. Lineage and the constructive imagination. In Bowern, Claire \& Bethany Evans (eds.). The Routledge handbook of historical linguistics, 45-63. London: Routledge.

Lass, Roger. 2015b. Interpreting alphabetic orthographies: Early Middle English spelling. In Honeybone, Patrick \& Joseph Salmons (eds.). The Oxford handbook of historical phonology, 100-120. Oxford: Oxford University Press.

Meillet, Antoine. 1964 [1937]. Introduction à l'étude comparative des langues Indo-européennes. 8th edition Paris: Hachette. Facsimile 1964. Alabama: University of Alabama Press.

Meralli, Zeeya. 2015. Quantum physics: what really exists? Nature News Feature. www.nature.com/news/quantum-physics-what-is-really real?/www.nature com. Last accessed 13 August 2017.

Saussure, Ferdinand de. 1879. Mémoire sur le système de voyelles dans les langues indo-européennes. Leipsick: Teubner. [Published 1878 with date 1879.]

Sweet, Henry. 1877. A handbook of phonetics. Oxford: Clarendon Press.

Zawadowski, Leon. (1962). Theoretical foundations of comparative grammar. Orbis 11. 5-20. 